\title{
Advantages of Using Technical Analysis to Predict Future Prices on the Amman Stock Exchange
}

\author{
Jumah Abbad $^{1}$, Bashar Fardousi ${ }^{2}$ \& Muneer Abbad ${ }^{3}$ \\ ${ }^{1}$ Associate Professor, The First Main Reseacher (Presnted for Sabbatical Leave), Financial and Banking \\ Department, Faculty of Finance and Business Administration, Al al-Bayt University, Jordan \\ ${ }^{2}$ Financial Markets researcher, Demascus, Syria \\ ${ }^{3}$ Business School, Hashemite University, Zarqa, Jordan \\ Correspondence: Jumah Abbad, Faculty of Finance and Business Administration, Al al-Bayt University, Mafraq, \\ Jordan. E-mail: drabbad@aabu.edu.jo
}

Received: August 8, 2013

Accepted: November 4, $2013 \quad$ Online Published: January 22, 2014

doi:10.5539/ijbm.v9n2p1

URL: http://dx.doi.org/10.5539/ijbm.v9n2p1

\begin{abstract}
Many studies have examined the benefits of conducting technical analysis on the stock market, with mixed results. With a view to clarifying the usefulness of technical analysis, this paper examines the capacity of technical analysis rules to predict future prices on the Amman Stock Exchange. As data for this research, a sample of closing prices for the general index on the Amman Stock Exchange was used. Our results show that technical analysis does have the power to predict the movement of the stock price, and to generate profitable buy and sell signals.
\end{abstract}

Keywords: technical analysis, fundamental analysis, Amman Stock Exchange

\section{Introduction}

Millions of business firms' shares are traded every day in financial markets all over the world. Most investors in making a profit from stock market shares seek to predict the potential future value of these shares, and use technical and/or fundamental analysis for this purpose.

There is however, an argument between those who favour a technical approach, and those who favour a fundamentalist approach as to the profitability of technical analysis. Technicians contend that their use of technical analysis alone will lead to signitifant profits, while the fundamentalists claim that such profits can be made without the use of any technical approach. Recognising this tension, many studies have been carried out in different countries such as the USA, Japan, China, Spain, and so forth, to examine the profitability of technical analysis rules in predicting the stock market. Such studies however do not generally concur on their results.

In this current study, we will examine whether or not technical analysis rules can be applied to predicting share movements on the Amman Stock Exchange, and whether such rules have the capacity to generate profitable buy and sell signals.

Plummer (1989, p. 20) stated that "although technical trading rules have been used in financial markets for over a century, it is only during the last twenty years of the last century, when there has emerged growing evidence that financial markets may be less efficient than originally believed, that the academic literature has shown an increased interest in such rules".

Furthermore, as cited in Andrada et al. (1999), Allen and Taylor (1992) conducted a survey showing that technical analysis has generally been a popular tool to inform the buying and selling decisions of stock market participants. They found 90 perecent of their respondents admitted placing an important part should be saved to technical analysis in relation to the time.

The main explanation for the increasing importance given to technical analysis is that traders have found this approach much easier to follow than the fundamental analysis approach, which in contrast needs a great deal of information about security, market, economy, politics and so on, and is time consuming in the considerable efforts needed to analyze scuh a large quantity of data. This paper, in seeking to clarify the efficacity of the technical analysis approach, is organized as follows: section 1 reviews the literature and sets the hypothesis. 
Section 2 presents the theoretical framework of the study, followed by Section 3, which discusses the data on technical trading rules. Finally, section 4 presents the concluding remarks.

\section{Literature Review}

Many studies have examined the benefits of conducting technical analysis on the stock market, with mixed results. For example, Marshall (2007) investigated whether an intraday technical analysis was profitable in the U.S. equity market in the period 2002-2003, and found that technical analysis was more valuable in the short time horizon. Also technical analysis has many other aspects. For example, some researchs proved that order clustering could support the technical analysis. Marshall's study (2007) tested five rules: Filter, Moving Average, Support and Resistance, Channel Breakout, and On-Balance Volume Rules of the profitability of 7,846 firms. The author proved that intraday technical analysis over the 2002-2003 was not profitable on the SPDR series. Prior to any formal adjustment for data snooping bias, there was evidence that a small number of rules could be profitable. From these results, the author found that there was no evidence of consistent inefficiency in the intraday SPDR data.

Underpinning these findings is a study by Marshall (2008) who found that the technical analysis was not profitable tool once it is applied on large stocks in the Japanese market over the 1975-2004. Marshall (2008) was examining candlestick test in the Japanese equity market. They assume the popularirty of these tests for the following reasons. Firstly, candlestick technical analysis appears to be culturally and historically well embedded in Japanese trading. Secondly, other technical trading rules have been shown to be more profitable in Japan than in the U.S.

Marshall (2007) used the bootstrap methodology and they applied the software to ensure the consistency with their paper. The results showed that no evidence the candlestick technical analysis was profitable when applied to the 100 largest stocks listed on the Tokyo stock exchange over the period 1975-2004. They argued that the test was not profitable for most of stocks for any of the sub-periods or in bull or bear markets.

Andara et al. (1999) was trying to investigat the possibility of the technical rules could return forecast power. He applied the test on the General Index of the Madrid Stock Exchange (IGBM), using daily data for the thirty-one-year period from 1966 to 1997 . He tested simple forms of technical analysis and his results indicated that technical test generated buy signals that consistently yielded higher returns than sell signals, suggesting that technical analysis did have power to forecast price movements. Also, the results showed that the returns that following the buy signals appeared to be less volatile than returns on sell signals. From these results, the evidence could indicate the existence of nonlinearities in the IGBM data generating mechanism. Moreover, the author found that returns following sell signals were negative.

Chiung-Hon (2006) proposed and used a fuzzy time series data representation method based on the Japanese candlestick theory. The proposed approach is applied to financial time series forecasting problem for demonstration. By the prototype system which has been established, the investment expertise can be stored in the knowledge base, and the fuzzy candlestick pattern can also be identified automatically from a large amount of the financial trading data.

Xiao-Ming and Kong-Jun (2006) made their analysis on the Shenzhen Stock Exchange in order to examine the usefulness of technical analysis. They used 8 years data of daily stock prices and trading volume of 39 companies listed on the market. The results showed that a very weak evidence in support of return predictability. The results indicated that the technical analysis can't predict the future price movements in China's stock markets and challenged the views of market inefficiency for China that were based on aggregate market data rather than individual company data.

Tsung-Jung (2011) study refers to the simulation results of several international stock markets, including the Dow Jones Industrial Average Index (DJIA), London FTSE-100 Index (FTSE), Tokyo Nikkei-225 Index (Nikkei), and Taiwan Stock Exchange Capitalization Weighted Stock Index (TAIEX). As these simulation results demonstrate, the proposed system is highly promising and can be implemented in a real-time trading system for forecasting stock prices and maximizing profits.

Ramsey (1990) used the daily Dow Jones Industrial Average Index for the period 1897 to 1988 to test the linear and nonlinear predictability of stock market returns with simple technical trading rules. The results showed that a strong evidence of nonlinear predictability in the stock market returns by using the past buy and sell signals of the moving average rules.

Thira Chavarnakul (2008) explores the profitability of stock trading by using a neural network model developed to assist the trading decisions of the VAMA and EMV. The generalized regression neural network (GRNN) is 
chosen and utilized on past S\&P 500 index data. His idea is to exploit the equivolume potential by using a forecasting system to predict the future equivolume measurements, allowing investors to enter or exit trades earlier. The results show that the stock trading using the neural network outperforms the results of stock trading generated from the VAMA and EMV without neural network assistance, the simple moving averages (MA) in isolation, and the buy-and-hold trading strategy.

Detry (2001) confirms that many other authors have discovered that the technical analysis in simple forms possess significant forecast power to predict various market indexes. He showed that such results can be replicated on formally selected European indexes. In addition, the author discussed in his paper the implications of these results in terms of market efficiency.

\subsection{The Problem of This Study}

Amman Stock Exchange is not only an active market in the Middle East, but moreover is situated at the heart of Middle East social and political activities that affect the market, and reflective of events such as the American invasion of Iraq and the Israeli attack on Lebanon. In this situation, many investors believe that technical analysis of this market can not be used to generate any profitable buy and sell signals, or to make profits. A main aim of this paper is to determine whether or not such claims are reliable.

\subsection{Hypothesis}

1) The importance of technical analysis is increasing, even while fundamentalists claim that is useless. In order to clarify this issue, this study aims to determine to what extent it is true that technical analysis can be used to generate more profits.

H0: using technical analysis can not generate profits.

H1: using technical analysis can generate profits.

2) Positive returns can be generated from buy signals.

$\mathrm{H} 0: \mathrm{RBS}<0$.

$\mathrm{H} 1: \mathrm{RBS} \geq 0$.

3) Positive returns can be generated from sell signals.

H0: RSS $<0$.

$\mathrm{H} 1: \mathrm{RSS} \geq 0$.

RBS: stands for return from buy signal;

RSS: stands for return from sell signal.

\section{Data and Methodology}

Data was collected from Amman Stock Exchange, to include the daily closing price for the General Index and covering the period from January 2000 to April 2007. This period was used to avoid the effect of the finaincial crisis on the reaserch's results. A simple moving average of rules was used with envelopes around it. This moving average was used because it was considered the most common technical analysis tool and would serve to eliminate small movements in the market. The time period in which this measure was applied served as a useful indicator for long term investement. The envelopes - meant that we could put two bands around the moving average (upper-band, lower-band) to eliminate data from being collected from false signals which didnot exceed one to three percent of the price. This envelope was called the price filter. Another filter used was the time filter which served to eleiminate false signals which didnot last more than ten days.

\subsection{Theoretical Framework}

\subsubsection{Financial Analysis}

The financial analysis in the study incorporates historical data related to securities, to gain information about the current and future financial health of a company and predict the future value of its assets. Those who are most concerned with the evaluation of securities are investors, who will buy or sell shares depending upon their calculating whether these shares are on the right or wrong side of the market. This paper focuseson this group of people. Others who are equally concerned about the predictability of the market are the management staff of corporations who are looking to increase the wealth of their shareholders. These also will be using financial analysis, in order to know to what extent their policies will enhance the goals of their shareholders. This financial analysis has two major approaches; fundamental and technical analysis. 


\subsubsection{Fundamental Analysis}

As Rector (2003) explains in his thesis on technical analysis in financial markets, fundamental analysis derives from a theory called firm-foundation theory that developed in 1930. The theory was popularized by Graham's book "The Intelligent Investor" (1949). These explain that fundamental analysis is a method for evaluating the intrinsic value of a security. This is done by examining related economic, financial and other qualitative and quantitative factors. Thus, fundamental analysts attempt to find and study all economic variables that can affect the future earnings of a financial asset. These variables measure different economic ircumstances, including macroeconomic factors, industrial factors and corporation factors.

The target of doing the fundamental analysis is to produce a value that can compare with the securities' current prices, in the hope of predicting the optimum position to take with that security (if it is seen as underpriced, then buy, overpriced then sell or short). This value is called the fundamental value or the true underlying value.

The philosophy behind fundamental analysis is to force the price of the asset to converge to its fundamental value. It is assumed that fundamental analysts who have better access to information and who have a more sophisticated system in interpreting will earn more than other analysts.

However, the traders can perform a complete fundamental analysis to evaluate the asset. It is important to examine a lot of different economic variables and that they have to know the precise effects of all these variables on the future cash flows of the asset. Therefore, it couls be argued, fundamental analysis is better for focused and long-term investment, since the trader who wishes to allocate his wealth between many short-term markets will find the market analysis very challenging. Therefore, the trader who wants to avoid such difficulties is obliged to move to Technical Analysis.

\subsubsection{Technical Analysis}

Technical analysis is "a study of the market action (price-volume-open interest), primarily through data derived from the use of charts for the purpose of forecasting future prices" (Murphy, 1999). During the study of price action, the trader looks for specific patterns, or rules, which can be used to generate buy and sell signals on the charts, and to use these signals to maximize returns and minimize the risks of his trades. The technical approach is based on three assumptions:

- The market discounts every thing;

- Prices move in trends;

- History repeats itself.

The market discounts everything is probably the cornerstone premise of technical analysis, and fundamental to the understanding of the TA approach. This premise means that everything may affect the price of a commodity; this political, psychological, social variable and so on may all influence and be reflected in the price chart of the market. Technicians therefore believe that if prices rise, this means that demand has exceeded the supply. They do not concern themselves with the reasons why prices move. In other words, they believe that there are reasons why prices move, but they believe also that knowing these reasons is not necessary. That prices move in trends is another important concept in technical analysis. The main reason for charting market prices is to determine trends during the early stages of trading. The principle is that the trader will follow the direction of the trend, and ride it until he finds a sign of reversing. That history tends to repeat itself is another important idea in technical analysis, mainly in terms of price movement.

\subsection{Types of Chart}

There are four main types of charts that are used by investors and traders depending on the information that they are seeking and their individual skill levels. The chart types are the line chart, the bar chart, the candlestick chart and the point and figure chart (see Figure 1,2,3 and 4). 


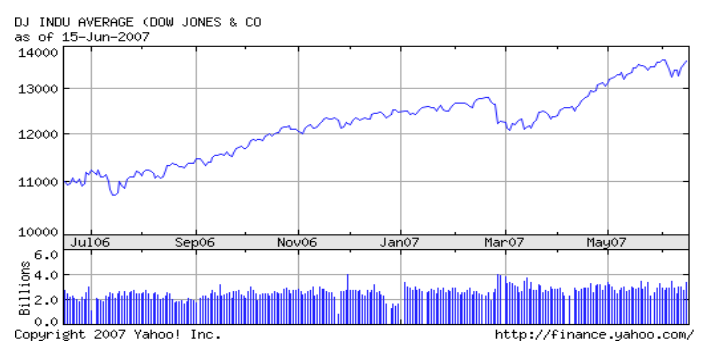

Figure 1. Line chart

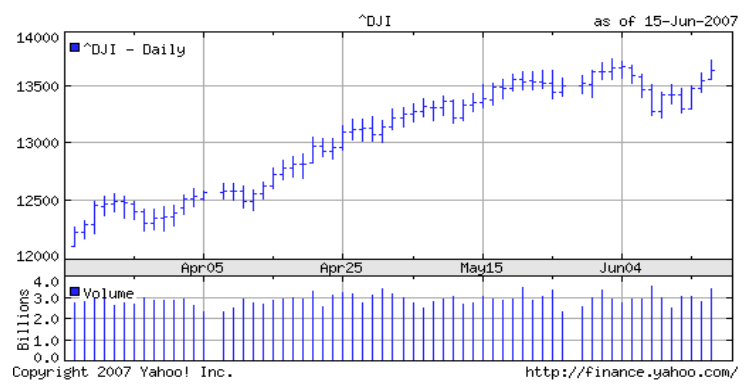

Figure 2. Bar chart

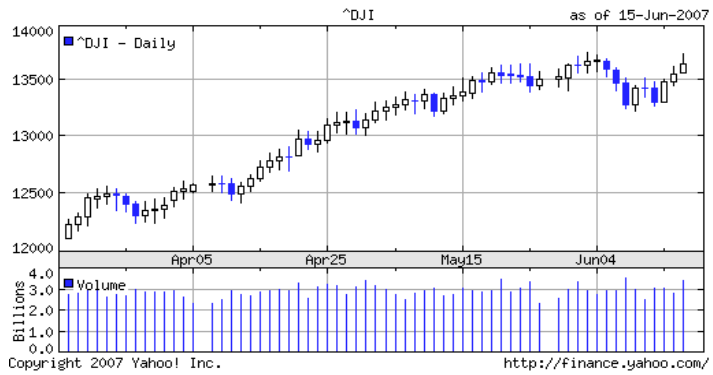

Figure 3. Candlestick charts

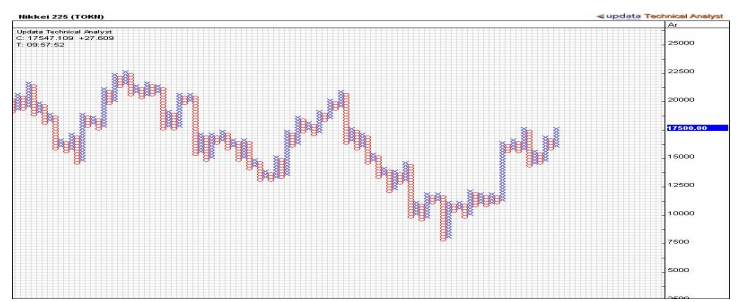

Figure 4. Point and figure charts

\subsection{The Most Used Technical Tools}

-Volume

Volume is simply the number of shares or contracts that are traded over a given period of time, usually a day. Volume is usually plotted on the bottom of the chart under the price, by means of vertical bars. If the volume is increasing, the current price trend will probably continue. If the volume is decreasing, the current trend will probably change its direction (see Figure 5). 


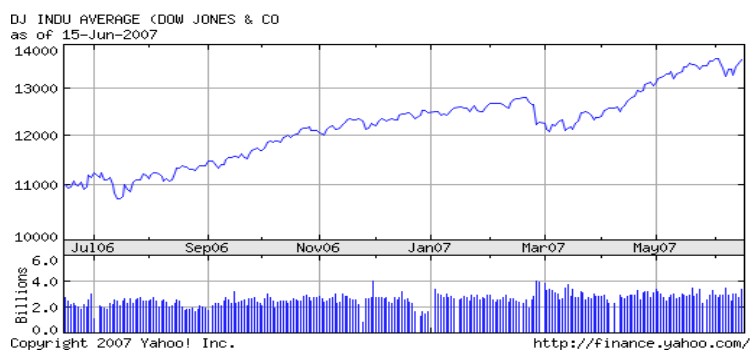

Figure 5. Technical tools-volume

\section{-On-Balance Volume (OBV)}

The OBV indicator is a famous technical indicator that reflects movements in volume. It is also one of the simplest volume indicators to compute and understand.

Murphy (1999, p. 165) stated that "OBV actually produces a curving line on the price chart. This line can be used to confirm the quality of the current price trend or to warn of an impending reversal by diverging from the price action". During this indicator, the direction of OBV is more important than the volume itself (see Figure 6).

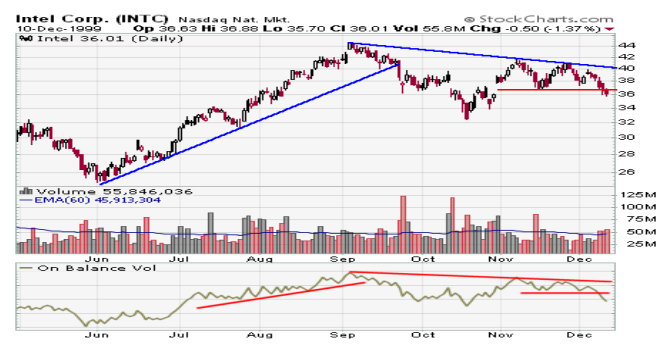

Figure 6. Technical tools-on-balance volume (OBV)

\section{-Relative Strength Index (RSI)}

Plummer (1989) explains that "the RSI is one of the most used and well-known momentum indicators in technical analysis. RSI helps to signal overbought and oversold conditions in a security. The indicator is plotted in a range between zero and 100. A reading above 70 is used to suggest that a security has been overbought, while a reading below 30 is used to suggest that it has been oversold. This indicator helps traders to identify whether a security's price has been unreasonably pushed to current levels and whether there is impending reversal". The most important thing we can say about the RSI, is that it is a leader. It tells us that there is a pending change in the trend, and it is useful in trendless markets (see Figure 7).

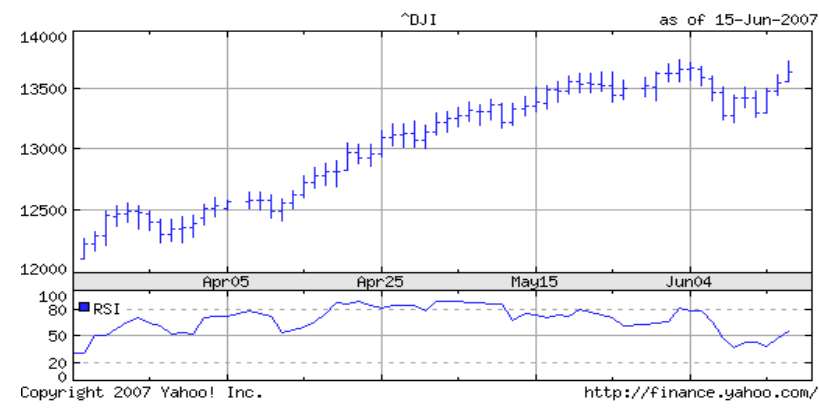

Figure 7. Technical tools-relative strength index (RSI) 


\section{-The Moving Average}

A moving average is the average price of a security over a set period of time. It is a smoothing tool, used to plot a security's average price. By means of the moving average, daily price fluctuations are removed, traders are better able to identify true trends, and to increase the probability that these trends will work in their favor. "The moving average is essentially a trend following device" (Murphy, 1999), indicating that a new trend has begun (see Figure 8).

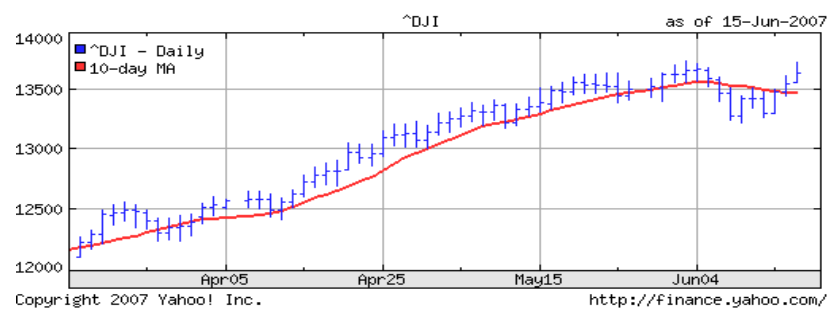

Figure 8. Technical tools-the moving average

There are many types of moving average:

1) Simple Moving Average (SMA)

As Murphy (1999) indicates, this is the most common used moving average. It simply takes the sum of all of the past closing prices over a specific period and divides the result by the number of days used in the calculation. However, this technique attracts two criticisms: firstly, this method takes into account only the data in the covered period, and secondly, this method gives equal weight to all the data.

\section{2) Linear Weighted Average}

This moving average is the least common of the three types. It addresses the problem of the equal weighting. The linear weighted moving average gives more weight to recent data, but it still takes into account the rest of the data in the covered period.

\section{3) Exponential Moving Average (EMA)}

This moving average gives more weight to recent data, while taking into account all past data. It is not straightforward to calculate this type of moving average, but computers do this task in all the technical analysis programs.

\subsection{Fundamental versus Technical Analysis}

Moving from one market to another fundamentally requires gathering and analyzing a great deal of information. The need for so many economic variables makes fundamental analysis in this respect more costly and difficult, whilst technical analysis has an advantage over fundamental analysis in that it can be applied reasonably easily and cheaply to all markets. It does require practice and skill in order to recognize patterns, but in principle anyone can apply such methods.

An advantage of technical analysis, it is easier to test the forecasting power of technical trading rules than to test the forecasting power of trading rules based on fundamentals. The main difference between chart analysis and fundamental economic analysis is that the chart analysis is studying only the price action of the market itself, whereas the fundamental analysis is looking for the reasons behind that action. However, both of them use the historical data.

It is not possible for technicians and fundamentalists to work in isolation from the support of the other. The technician needs the important information from the fundamentalist in order to enhance his decisions, whilst on the other side, the fundamentalist needs to use the technical data at least as an indicator of timing since this answers the most important question in trading, when to enter and exit the market.

\subsection{Criticisms of Technical Analysis}

In any discussion about technical analysis, many questions arise. The first and the most important one is whether this approach acts as a self-fulfilling prophecy, followed secondly by whether past prices can be used to predict future prices. In regard to these two questions the general response is that "technical analysis tells us where the market has been, but can not tell us where it is going" (Murphy, 1999, p. 15). 
Nevertheless, for the purposes of this paper we will address the two questions with some detail:

The self-fulfilling prophecy: Murphy (1999, p. 15) notes two disadvantages to using chart patterns. He suggests that because most traders are familiar with publicized chart patterns, there is a tendency to act upon them in concert, creating a self-fulfilling prophecy. In this respect, Murphy remarks that "chart patterns are almost completely subjective. No study has yet succeeded in mathematically quantifying any of the beholders" (ibid.).

However, it would seem that these two criticisms tell us completely opposite things. Murphy's first comment suggests that chart patterns are objective, in giving all traders the same information and thus equal opportunity to predict the future. On the other hand, his second comment suggests that chart patterns are open to subjective interpretation that it is likely no two traders would arrive at the same opinion. We would argue that these criticisms of technical analysis are paradoxical; if patterns are "completely subjective" and "in the mind of beholder", then it is difficult to imagine that all traders would interpret the charts in the same way.

Perhaps it could be more plausibly argued that chart reading is definitely subjective, and that it is normal to find many chartists of different opinion on the same chart, responding to it in different ways. This would imply that even if chartists shared similar predictions on the future of shares, this would be no guarantee that they would enter or exit the market at the same point of time.

Another criticism of technical analysis leveled by Murphy (1999, p. 17) is that "technicians could not possibly cause a major market move just by the sheer power of their buying or selling. If this were the case, technicians would all become wealthy very quickly". We would argue that this criticism is not true for technical analysis, but rather, leveled at fundamental analysis, which gives almost the same results to all analysts.

Is it possible to use past prices to predict the future?

This question seems to contain a contradiction, in that we already know that the majority of sciences use carries through and apply past data to bringing about results can be used for the future. Statistical data can be divided into descriptive statistics and inductive statistics. Descriptive statistics refer to the graphic presentation of data the type of which can be foundon price charts. Inductive statistics refer to predictions that can be inferred from descriptive statistics. This type of inference is what technical market analysts, who use do past prices to predict future prices based on statistical concepts. Logically speaking, if the use of past prices to predict future prices was of no use to techincal analysts, it would follow that historical data is of no used for any field, including fundamental analysis.

\subsection{Data and Technical Trading Rules}

The database used is composed of (1800) observations of daily closing prices of the general index of Amman Stock Exchange (see Figure 9). This index is sufficiently representative of the Amman stock market.

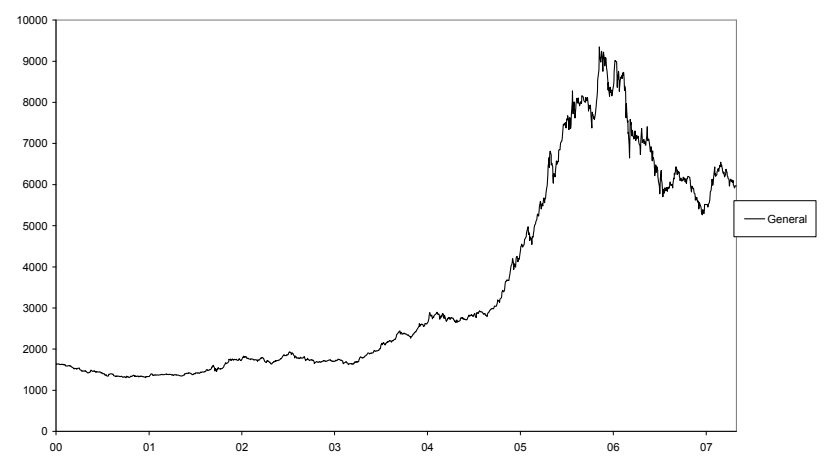

Figure 9. Data and technical trading rules

Drawing from previous academic studies and the technical analysis literature, the simple moving average will be used in this paper. Andera et al. (1999) stresses the substantial danger of detecting spurious patterns in security returns if trading strategies are both discovered and tested in the same database. Andera et al. (1999) back up this view. Therefore to mitigate the danger of data snooping bias we used the price filter.

According to the moving average move buy (sell) signals by the simple moving average when the prices close above (below) the moving average. The moving average is essentially a trend following device, its purpose is to 
identify or signal that a new trend has begun or that an old trend has ended or reversed; the moving average is a follower not a leader.

We evaluated the following popular moving average rules: 50 days moving average (50MA), 100 days moving average (100MA), and 150-days moving average (150 MA). These rules are often modified by introducing a band around the moving average, which reduces the number of false buy (sell) signals by eliminating "whiplash" signals when the moving average and the closing prices are close to each other. We are going to evaluate two moving average trading rules: The first moving average rule that examined was the variable length moving average (VMA), also known as the price filter. This implies that a buy (sell) signal is generated when the closing prices are above (below) the moving average by more than three percent. If the closing price is inside the band, no signal is generated. This method attempts to simulate a strategy where traders go long while the price is moving above the moving average and short when it moves below. With a band of zero, this method classifies all days into either buys or sells. The second moving average trading rule that analyzed was the fixed-length moving average (FMA), also known as the time filter. Since it is stressed that returns should be different for a few days following a crossover, in this strategy a buy (sell) signal is generated when the closing prices cut the moving average from below (above).

\section{Empirical Results}

In this section we will follow the same steps that Andera et al. (1999) followed in his paper.

Panel A and B in Table 1 report summary statistics for daily and 10-day returns series, respectively. Returns were calculated as daily changes in logarithms of the Amman Stock Exchange index level, and thus excluded dividends yields. As can be seen, these daily returns exhibited high Kurtosis and (marginal) negative Skewness, indicating nonnormality in returns (peaked distribution, and not symmetric).

10-day returns exhibited high Kurtosis and positive Skewness which indicates also nonnormality in returns (peaked distribution, but symmetric).

Table 1. Summary statistics for daily and 10-days returns

\begin{tabular}{ll}
\hline Panel A: Daily returns & \\
\hline Sample Size & 1810 \\
Mean & 0.0007 \\
Standard Deviation & 0.011 \\
Skewness & -0.0689 \\
Kurtosis & 2.77 \\
\hline & \\
Panel B: 10-days returns & \\
\hline Sample Size & 181 \\
Mean & 0.0069 \\
Standard Deviation & 0.0366 \\
Skewness & 0.0438 \\
Kurtosis & 0.92 \\
\hline
\end{tabular}

If technical analysis does not have any power to forecast price movements, then we should observe that returns on days when the rules emit buy signals would not differ appreciably from returns on days when the rules emitted sell signals. To evaluate the forecast power of technical trading rules, we computed the mean return and variance on buy and sell days for the rules described.

In Table 2 we present the results from VMA and FMA trading strategies. As mentioned above, we examined six rules $(1, b)$, differing by the length of the moving average (1), and by the size of the band (b: 0 or $3 \%)$. In particular, in Table 2 we report the number of buy and sell signals generated during the period ["N (Buy)" and "N (Sell)", respectively], the mean buy and sell returns ("Buy" and "Sell", respectively), the fraction of buy and sell returns greater than zero ("Buy $>0$ " and "Sell $>0$ ") and the difference between the mean daily buy and sell returns ("Buy-Sell"). "The t-statistics for the "Buy" ("Sell") statistics are computed using the following formula:

$$
\frac{\mu_{r}-\mu}{\sqrt{\frac{\sigma^{2}}{N}+\frac{\sigma^{2}}{N_{r}}}}
$$


where $\mathrm{r}$ and $\mathrm{Nr}$ are the mean return and the number of signals for the buys and sells, and and $\mathrm{N}$ are the unconditional mean and the number of observations. $\sigma 2$ is the estimated variance for the entire sample.

For the "Buy-Sell", the t-statistic is:

$$
\frac{\mu_{b}-\mu_{s}}{\sqrt{\frac{\sigma^{2}}{N_{b}}+\frac{\sigma^{2}}{N_{s}}}}
$$

where $b$ and $b$ are the mean return and number of signals for the buys, and $s$ and Ns are the mean return and the number of signals for the sells" (Andera et al., 1999).

Table 2. Standard results for the fixed-length moving average (FMA) rules

\begin{tabular}{|c|c|c|c|c|c|c|c|c|}
\hline Period & Test & N(buy) & $\mathrm{N}(\mathrm{sell})$ & Buy & Sell & Buy $>0$ & Sell $>0$ & Buy-Sell \\
\hline $02 / 01 / 2000$ & $(1,50,0)$ & 13 & 23 & 0.1289 & 0.0461 & 0.5882 & 0.7500 & 0.08276523 \\
\hline \multirow[t]{12}{*}{$30 / 04 / 2007$} & & & & (12.1683) & (3.5803) & & & $(6.5031)$ \\
\hline & $(1,50,0.03)$ & 24 & 21 & 0.1158 & 0.0258 & 1.0000 & 0.8571 & 0.09004095 \\
\hline & & & & (14.4473) & $(2.2270)$ & & & (8.2155) \\
\hline & $(1,100,0)$ & 14 & 5 & 0.1317 & 0.1102 & 0.7857 & 0.5385 & 0.02155684 \\
\hline & & & & (12.8736) & $(9.7976)$ & & & $(1.1281)$ \\
\hline & $(1,100,0.03)$ & 11 & 11 & 0.1435 & 0.0450 & 1.0000 & 0.7143 & 0.09856294 \\
\hline & & & & (12.5378) & $(2.6896)$ & & & $(6.3020)$ \\
\hline & $(1,150,0)$ & 6 & 6 & 0.2338 & 0.0057 & 0.7143 & 0.4000 & 0.22813939 \\
\hline & & & & (15.3144) & $(-0.0778)$ & & & (10.7733) \\
\hline & $(1,150,0.03)$ & 7 & 7 & 0.1188 & 0.0356 & 1.0000 & 0.8000 & 0.0831712 \\
\hline & & & & $(8.3580)$ & $(2.4066)$ & & & $(4.2422)$ \\
\hline & Average & & & 0.1454 & 0.0447 & & & \\
\hline
\end{tabular}

Notes: Rules are identified as $(1, b)$, where 1 is the length of the moving average (in days) and $b$ is the band (either 0 or $3 \%$ ).

"N(buy)" and "N(Sell)" are the number of buy and sells signals generated by the rule. "Buy $>0$ " and "Sell $>0$ " are the fraction of buy and sell returns greater than zero. Number in parentheses are standard t-statistics testing the difference, respectively, between the mean buy return and the unconditional mean return, the mean sell return and the unconditional mean return, and buy-sell and zero. The last row reports averages across all 6 rules.

We examined fixed 10-day holding periods after a crossing of the moving averages.

As can be seen in Table 2, the buy-sell differences are significantly positive for all rules. The introduction of the three percent band increased the spread between the buy and sell returns. The number of buy signals generated by each rule was found to be almost equal to the number of sell signals.

The mean buy returns were all positive, with an average 10-day return of 14.5 percent. All t-statistics reject the null hypothesis that the returns equal the unconditional returns (0.0069) percent from Table 1.

For the sells, also all means returns were positive, with an average 10-day return of 0.0447 percent, and all the t-statistics were positive, except one.This rejects the null hypothesis.

Regarding "Buy $>0$ " and "Sell $>0$ " statistics, the buy fraction was consistently greater than 50 percent and ranging between $0.588-1.00$. The sell fractions ranged between $0.40-0.85$.

Under the hypothesis that technical trading rules do not produce useful signals, these fractions should be the same: a binomial test shows that these differences are highly significant and the null hypothesis can be rejected.

These results are similar to those reported by Andrada et al. (1999), except the returns from sell signals, which suggests that technical analysis can not produce sell signals. 


\subsection{Chart Analysis}

In order to analyze the charts we used combinations of the simple moving average and envelopes around it. These combinations were $(50,0),(50,0.03),(100,0),(100,0.03),(150,0)$ and $(150,0.03)$, where the first number represents the length of the moving average and the second number represents the percentage of the envelope. Murphy (1999) illustrates that the most common combination is 50, 0.03 , or 10 weeks moving average with 3 percent bands. Therefore, we used this combination in the analysis.

All figures represent the daily closing price for Amman Stock Exchange.

-As we can see in Figure 10, at the beginning of April there was a sell signal, with the prices dipping under the lower band. In this situation the trader would be able to add new short positions to his positions or at least to feel comfortable with this decrease. From the middle of May until the end of October, the prices were ranging between the moving average and the lower band which indicates a market weakness. At the end of October the prices crossed the moving average from below; this crossing serves as a warning signal to close the short positions.

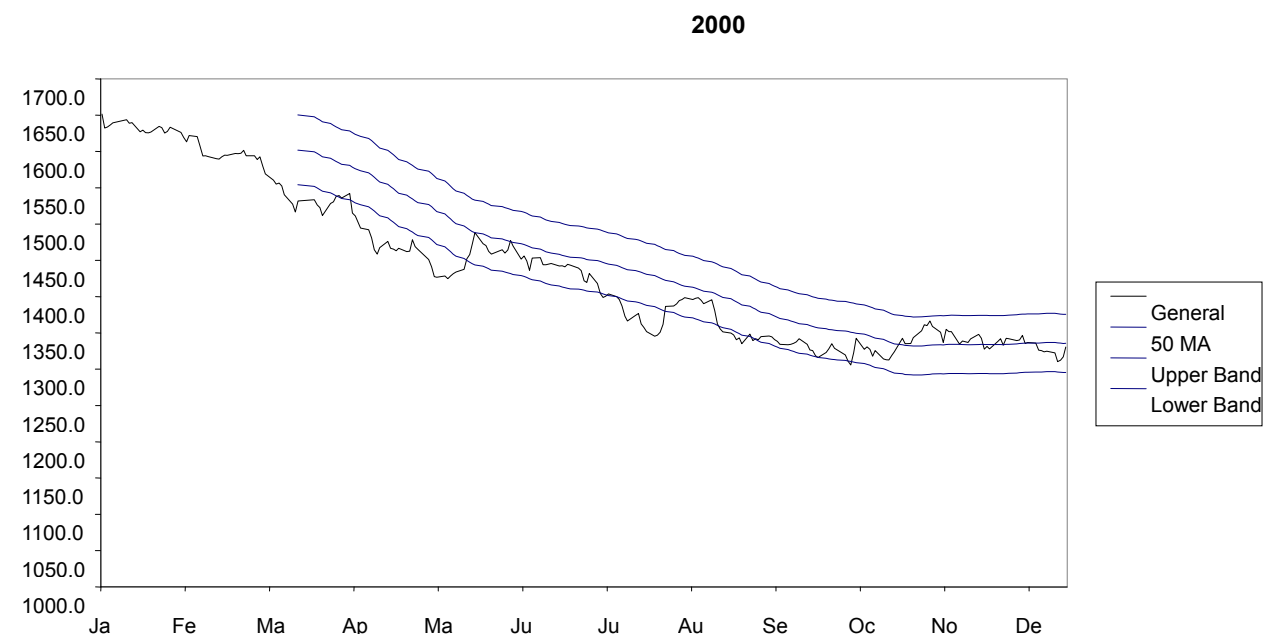

Figure 10. Closing price for Amman stock exchange index in 2000 with 50-day moving average and 3\% envelopes

-In 2001 (Figure 11) the prices were moving sideways until the end of May where the prices started to range between the moving average and the upper band until the middle of August. At this point, the prices rallied to cross above the upper band and gave a buy signal. In the middle of September, there was a correction, where the prices dipped under the moving average to rally again at the end of October, hitting a level of 1750 points.

2001

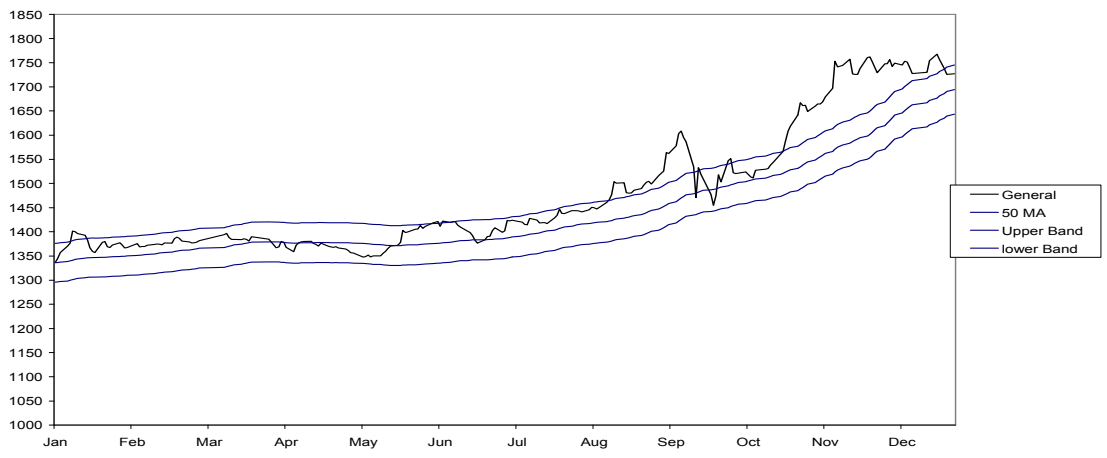

Figure 11. Closing price for Amman stock exchange index in 2001 with 50-day moving average and 3\% envelopes 
-From the beginning of 2002, the prices went downward until the middle of May, where they conveyed a buy signal to move downward in a correction wave, which lasted until October. They then moved up again and crossed the moving average at the end of November. This was a sign for the traders to close their short positions, Figure 12.

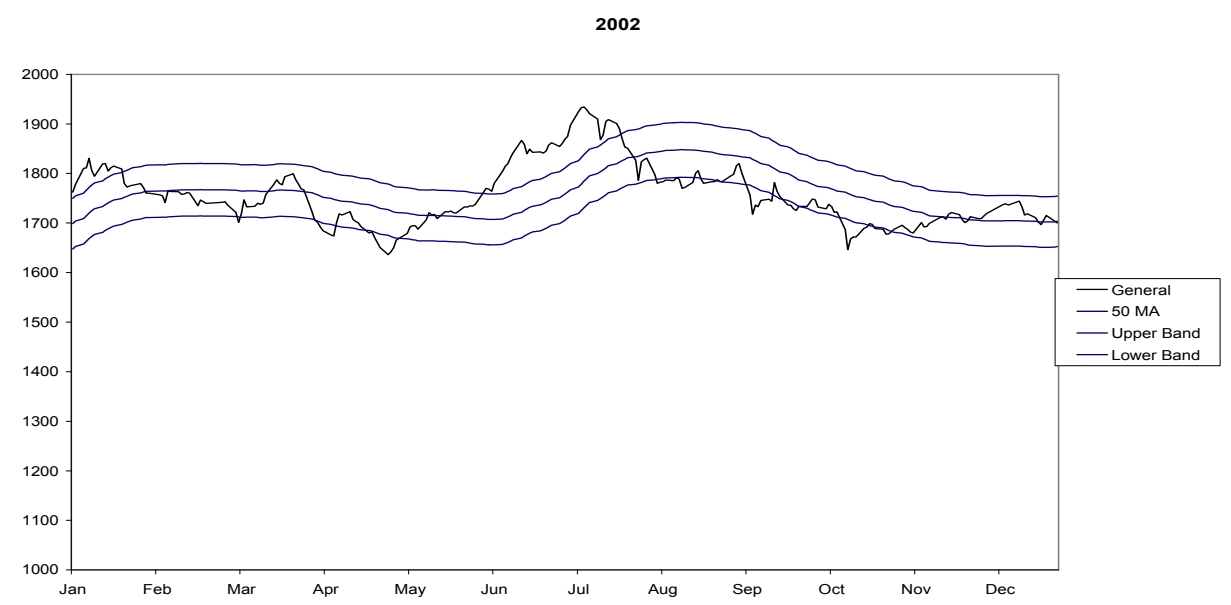

Figure 12. Closing price for Amman stock exchange index in 2002 with 50-day moving average and 3\% envelopes

-In 2003, the prices moved sideway until April to convey a buy signal. The price stayed moving upward until it corrected itself in October and thenrallied again at the beginning of November to hit the level of 2600 points, Figure 13.

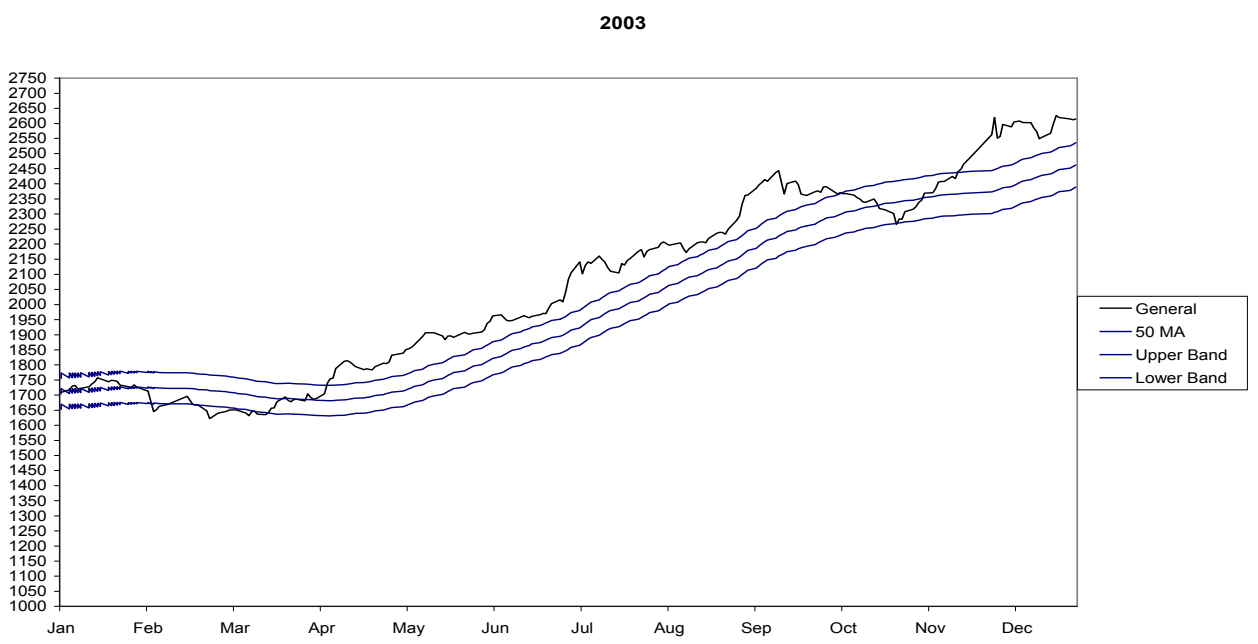

Figure 13. Closing price for Amman stock exchange index in 2003 with 50-day moving average and 3\% envelopes

-The market moved sideways in 2004 to correct itself until the end of August with a buy signal, where the price rallied to reach the level of 4200 points in the middle of December, Figure 14. 


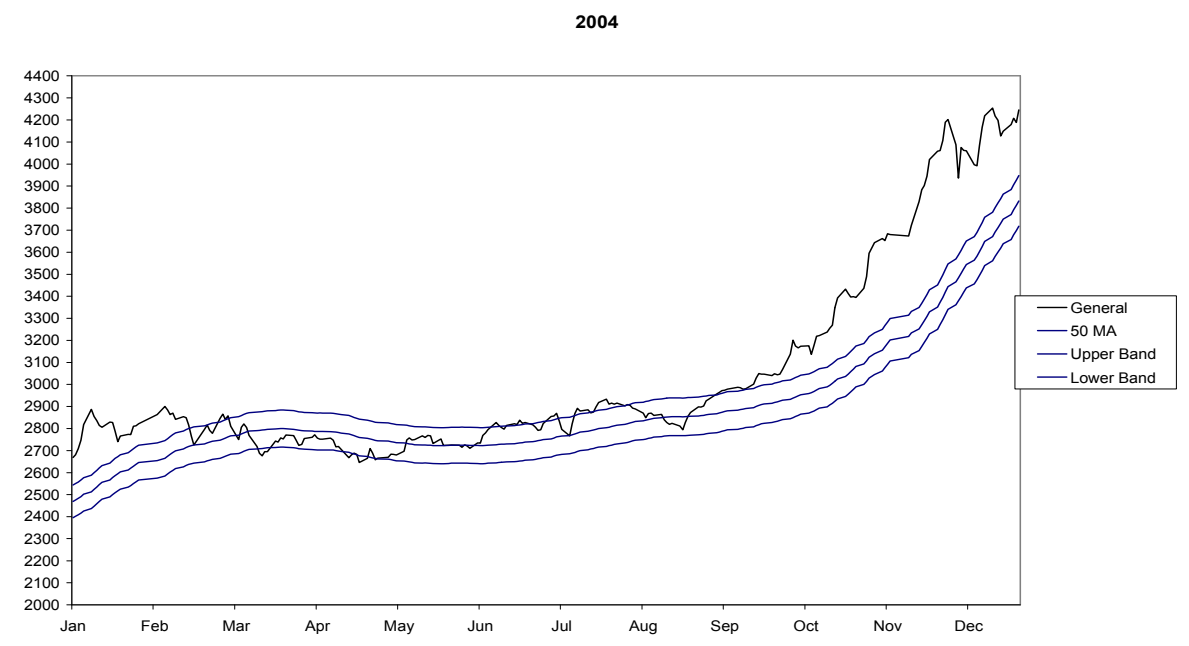

Figure 14. Closing price for Amman stock exchange index in 2004 with 50-day moving average and 3\% envelopes

-In 2005, on one hand the prices were moving upward until the beginning of November to reach 9350 points but there were many signs indicating that the uptrend would probably change direction. The first sign was the strong slope of the uptrend. The second sign was the corrections in Feb, May and Aug-Sep. with a false sell signal in October. Finally, there was a strong dip at the beginning of December. This suggests that traders would do well to be concerned for their positions in such situations, Figure 15.

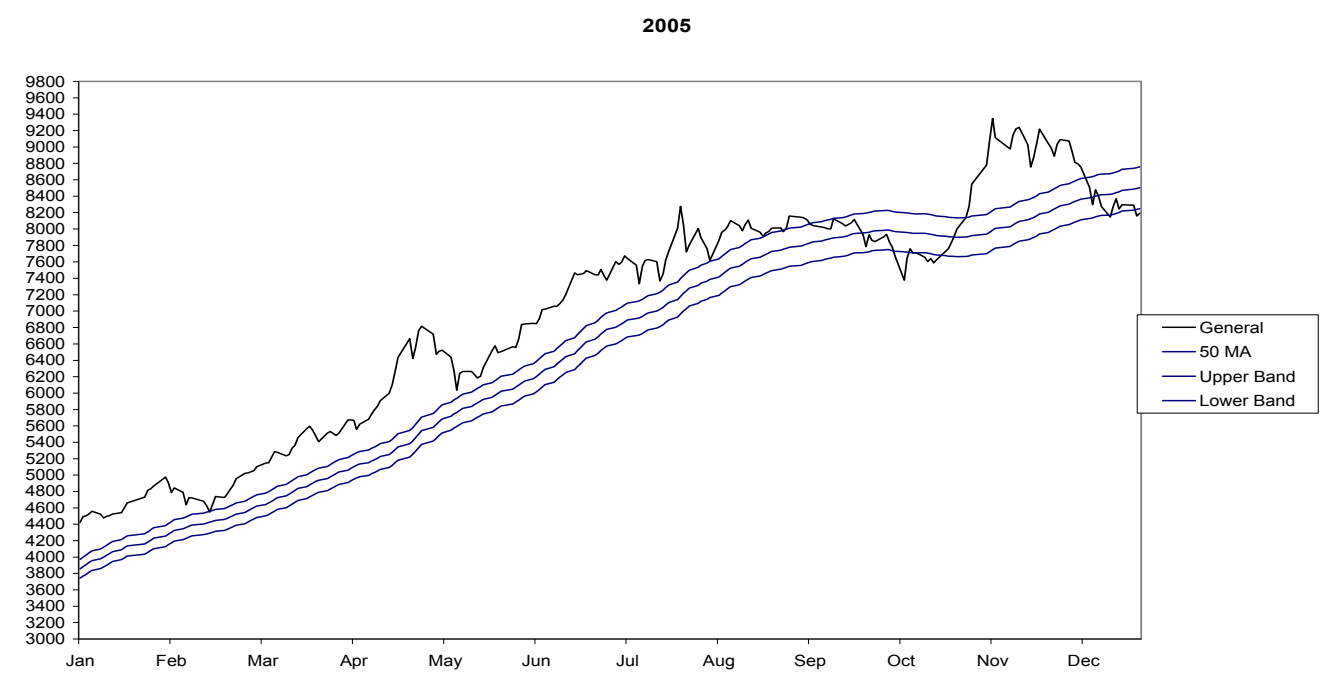

Figure 15. Closing price for Amman stock exchange index in 2005 with 50-day moving average and 3\% envelopes

-There was a sell signal at the end of February in 2006 after which the prices dipped sharply until March. In March, April and May the index was moving sideways in a correction period. Subsequently the prices continued to dip, hitting the level of 5350 points, Figure 16. 


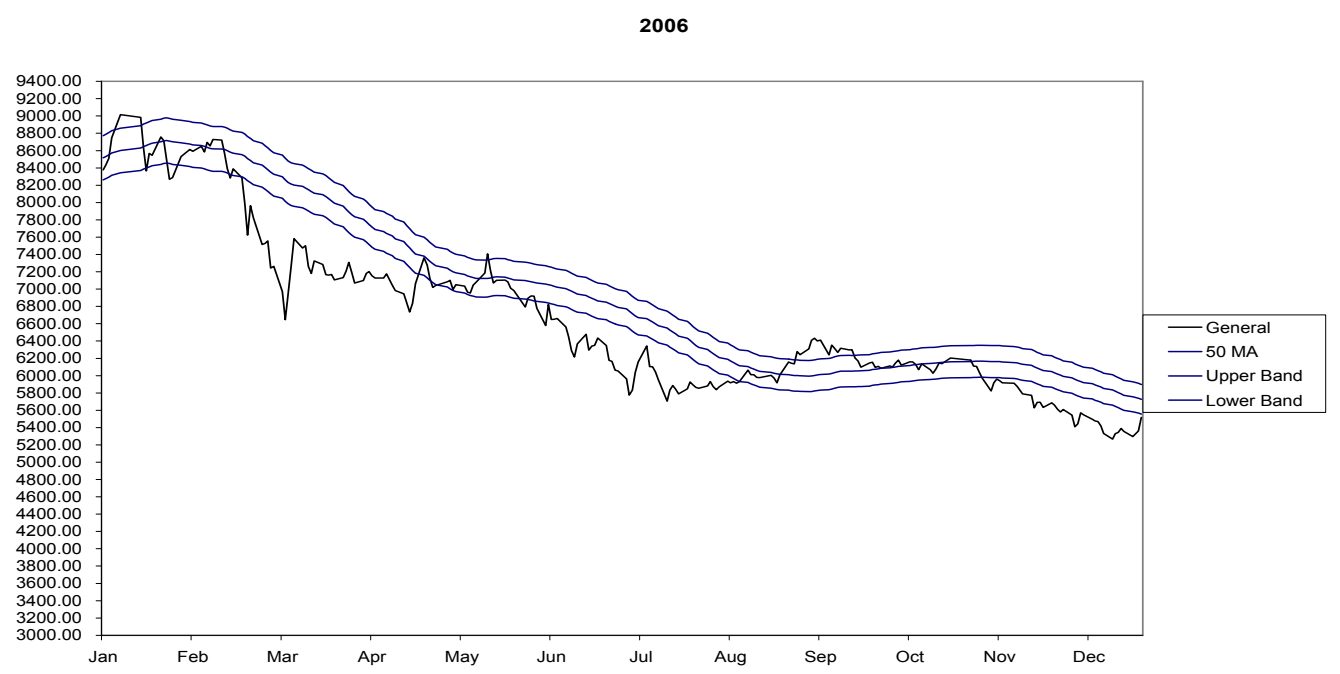

Figure 16. Closing price for Amman stock exchange index in 2006 with 50-day moving average and 3\% envelopes

-There was a buy signal in the middle of January 2007, and the prices stayed above the upper band until March to cross the upper band and the moving average, then into the lower band to convery a sell signal in the middle of April, Figure 17.

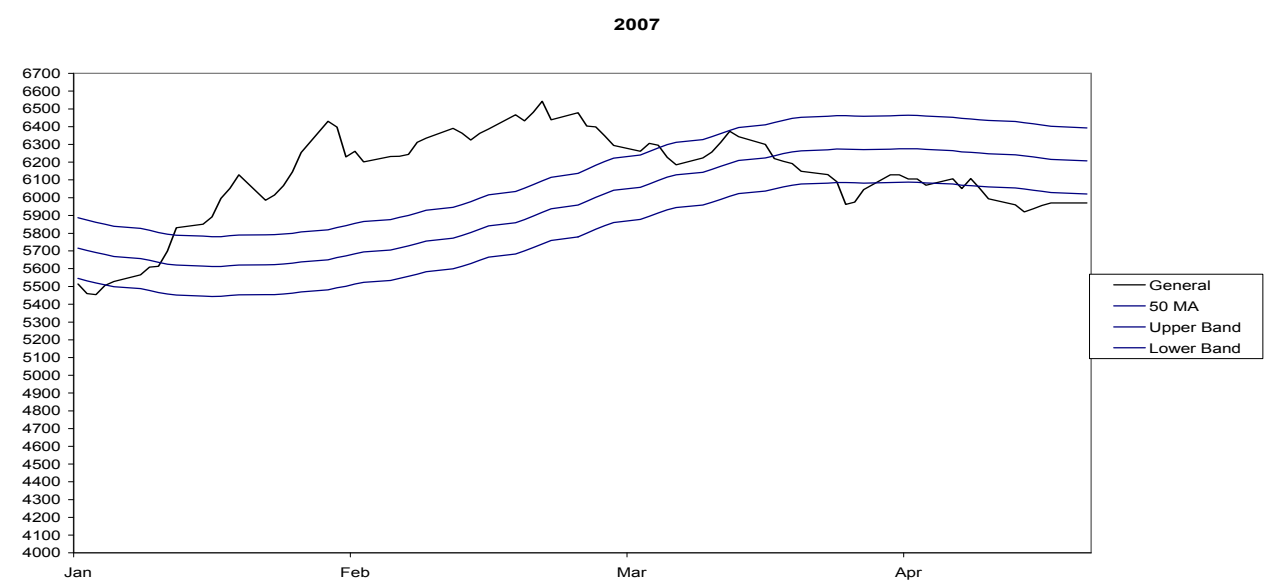

Figure 17. Closing price for Amman stock exchange index in 2007 with 50-day moving average and 3\% envelopes

We can see from these observations that technical analysis had the capacity to provide important signals that could be used to initiate or close positions. 


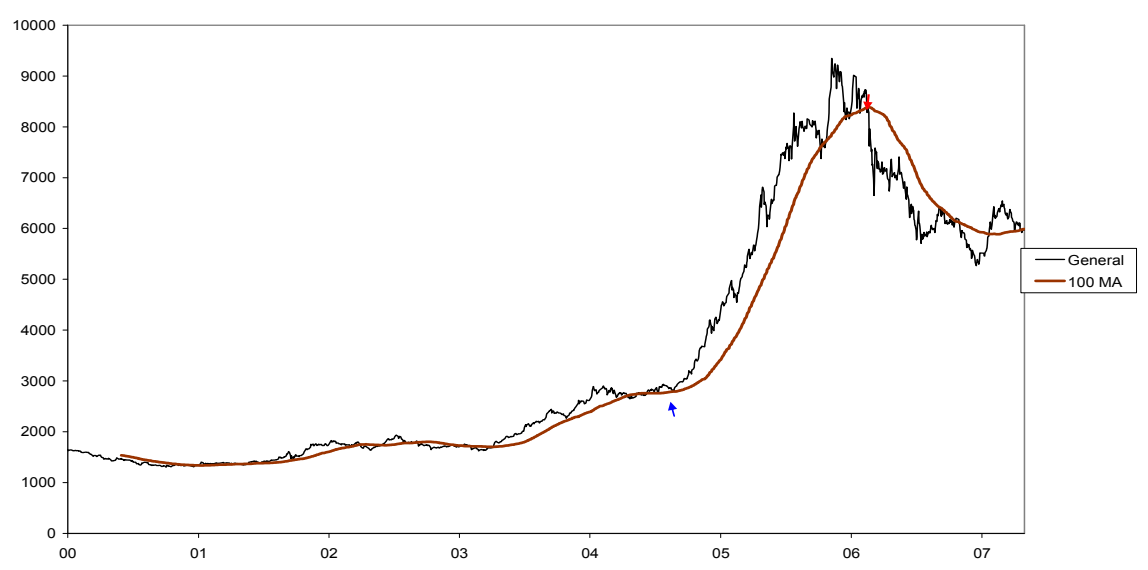

Figure 18. The closing price of the index for the whole period covered between 2000-2007 with a 100-day moving average

Figure 18 represents the closing price of the index for the whole period covered between 2000-2007 with a 100-day moving average. On this chart the price was moving sideways until 2003, when a buy signal was generated in March. In 2004 the index changed its direction and started to move sideways until the third quarter of that year, where the price rallied to exceeds the level of 9300 points. At the beginning of 2006, there was a top and the price dipped to sharply cross the moving average and generate a sell signal. Between March and May there was a correction and at almost the end of May, the prices again decreased sharply to reach the level of 5780 points. At the end of December 2006 there was a bottom and the there was a buy signal in the end of January 2007.

It should be noted in considering this data that during the period of the study, there were very important events in the Middle East, the American invasion to Iraq in 2003 and the Israeli attack on Lebanon in 2006.

The 20th of March 2003 was the beginning of the American invasion of Iraq. At this period of time, the Iraqi investors started to transfer and invest their money in other countries. In the opinion of the researcher, the Amman stock exchange received a huge amount of these investements which would explain the sharp rise in prices to hit the level of 9300 points.

At the end of 2005, there were two important events: the first one was a crash in the estates sector which indicates (in our opinion) that a large amount of investment moved over to this sector from the stock market. The second was the stock exchange committee's decision to force investors to pay a real margin to their brokers; this margin was not required before. These two events changed the direction of the prices which started to dip sharply.

In the middle of 2006, there were problems between Hezbullah and Israel, which ended with Israeli attacks on Lebanon. This event pushed the prices down-ward.

We can see clearly that all these important world events are reflected on the price charts of the time. This would indicate that technical analysis had noticeable power to produce more profits on the Amman Stock Exchange, then as now. This result supports the results in the previous section.

\section{Concluding Remarks}

This reaserch investigated the possibility that technical rules contain significant return forecast power. To that end, the reaserch evaluated simple forms of technical analysis for the Amman Stock Exchange index, using daily data for seven years from 2000 to 2007. The results suggest that technical trading rules generate buy and sell signals, suggesting that technical analysis does have power to forecast price movements.

Moreover, the results would indicate that the returns following buy signals are more profitable than returns following sell signals. Given that the period covered in this study is not very long, it is significant that so many important events are reflected in the charts. Therefore, the results of this reaserch provide strong support for profitability of simple technical trading rules.

Therefore we suggest the follow for the investors in the Amman Stock Exchange: 
The investors should be familiar with technical analysis rules, because these rules have the power to generate significant returns.

The first suggestion does not mean ignoring fundamental analysis, which investors should use for the important fundamental information it supplies. This would serve at least to enhance their technical decisions.

\section{References}

Allen, H., \& Taylor, M. P. (1992). The use of technical analysis in the foreign exchange market. Journal of International Money and Finance, 11, 304-331.

Andrada, J. F., \& Sosvilla, S. (1999). Technical Analysis in Madrid Stock Exchange. FEDEA.

Chiung-Hon, L. L. (2006). Pattern discovery of fuzzy time series for financial prediction. Knowledge and Data Engineering, 18(5).

Detry, P. J. (2001). Other Evidences of the Predictive Power of Technical Analysis: The Moving Averages Rules on European Indexes. University of Namur, Belgium.

Graham, B. (1949). The Intelligent Investor (4th ed.). New York: Harper \& Row, Publishers, Inc.,

Marshall, B. R. (2007). Does Intraday Technical Analysis in the U.S. Equity Market Have Value? Massey University.

Marshall, B. R. (2008). Are Candlestick Technical Trading Strategies Profitable in the Japanese Equity Market? Massey University.

Murphy, J. (1999). The Technical Analysis of the Financial Markets. New York Institution of Finance.

Plummer, T. (1989). Forecasting Financial Markets: The truth behind technical analysis. Kogan Page, London.

Ramsey, J. B. (1990). Economic and Financial Data as Nonlinear Processes. In Dwyer, G. P., \& R. W. Hafer (Eds.), The Stock Market: Bubbles, Volatility, and Chaos, Kluwer Academic. Boston: MA.

Rector, M. (2003). The Technical Analysis in the Financial Markets. Amesterdam University.

Thira, C. (2008). Intelligent technical analysis based equivolume charting for stock trading using neural networks. Expert Systems with Applications, 34(2), 1004-1017.

Tsung-Jung, H. (2011). Forecasting stock markets using wavelet transforms and recurrent neural networks: An integrated system based on artificial bee colony algorithm. Applied Soft Computing, 11(2), 2510-2525.

Xiao-Ming, L., \& Kong-Jun, C. (2006). On the Value of Technical Analysis for Stock Traders in China. Department of Commerce, Massey University (Albany), New Zealand.

\section{Copyrights}

Copyright for this article is retained by the author(s), with first publication rights granted to the journal.

This is an open-access article distributed under the terms and conditions of the Creative Commons Attribution license (http://creativecommons.org/licenses/by/3.0/). 